\title{
STUDY OF CD4 COUNT IN PRE-ART PERIOD AND DURING ART PERIOD IN SEROPOSITIVE HIV ADULT PATIENTS TO SEE THE EFFECT OF HAART
}

\author{
Brijesh Kumar1, Shri Krishna Gautam², Anita³, Lalit Kumar4, Pradeep Kumar5, Mohd. Imran Khan ${ }^{6}$ \\ ${ }_{1}^{1}$ Associate Professor, Department of Medicine, GSVM Medical College, Kanpur, Uttar Pradesh, India. \\ ${ }^{2}$ Associate Professor, Department of Medicine, GSVM Medical College, Kanpur, Uttar Pradesh, India. \\ 3 Medical Officer Family Planning, GSVM Medical College, Kanpur, Uttar Pradesh, India. \\ ${ }_{4}^{4}$ Senior Resident, Department of Medicine, GSVM Medical College, Kanpur, Uttar Pradesh, India. \\ $5 J u n i o r$ Resident, Department of Medicine, GSVM Medical College, Kanpur, Uttar Pradesh, India. \\ ${ }^{6}$ Senior Resident, Department of Medicine, GSVM Medical College, Kanpur, Uttar Pradesh, India.
}

\begin{tabular}{l}
\hline ABSTRACT \\
BACKGROUND \\
Cases of HIV are increasing all over the world. India is the third largest in terms of HIV epidemic. This disease has put economic \\
burden over the country. Hence we conducted this study to compare CD4 Count before starting ART and during ART period in \\
seropositive HIV adult patients. \\
Aims and Objectives-To study CD4 Count in pre-ART period and during ART period in seropositive HIV adult patients after 2 weeks, \\
4 months, 8 months, 16 months and 20 months of starting ART.
\end{tabular}

\section{MATERIALS AND METHODS}

This is a hospital based (observational) cohort study carried out between Dec 2015 to July 2017 among 100 adult HIV positive patients registered at ART-Plus centre, GSVM Medical College, Kanpur.

\section{RESULTS}

Among a total of 100 cases, 70\% were males of which majority belonged to younger age group of 20-40 (72\%) followed by 40-60 years (17\%). HIV infection is more common in married individuals $(73 \%)$ and in cases belonging to Hindu religion (61\%) followed by Muslims (36\%). Infection was more common in low socio-economic status. During the period of study, significant rise in CD4 count was noted during the ART period as compared to pre-ART period among study groups of all ages.

\section{CONCLUSION}

The use of ART in adult population of HIV showed a significant rise in CD4 counts both as an immediate ( 2 wks.) and long-term effect (20 months) as compared to pre-ART period of study and the rise in CD4 counts was progressive over the time period of this study. It was also concluded that there was more significant rise in CD4 count during 2 weeks to 4 months of ART in the younger age group of 18-20 years and 20-40 years. Since HIV is a global disease, with India being the third largest center for HIV epidemic in the word, ART should be started early in the HIV sero-positive patients irrespective of the CD4 count and staging. As it is more prevalent in younger reproductive age groups, these age groups should be better taken care off and educated regarding HIV and methods of its prevention.

\section{KEY WORDS}

HIV, ART, CD4 Count.

HOW TO CITE THIS ARTICLE: Kumar B, Gautam SK, Anita, et al. Study of CD4 count in pre-art period and during art period in seropositive HIV adult patients to see the effect of HAART. J. Evolution Med. Dent. Sci. 2019;8(06):381-384, DOI: $10.14260 /$ jemds/2019/84

\section{BACKGROUND}

\section{Global Burden of HIV}

At the end of 2016, an estimated 36.7 million people were living with HIV (including 1.8 million children)- a global HIV prevalence of $0.8 \% .^{[1]}$ The vast majority of this number live in low- and middle - income countries. In the same year, 1.0 million people died of AIDS-related illnesses worldwide.

'Financial or Other Competing Interest': None.

Submission 18-01-2018, Peer Review 25-01-2019,

Acceptance 31-01-2019, Published 11-02-2019.

Corresponding Author:

Dr. Anita,

H. N. 27 New Type IV Faculty Quarters,

GSVM Medical College Campus,

Kanpur-208002, Uttar Pradesh, India.

E-mail:dr.gautamhal@gmail.com

DOI: $10.14260 /$ jemds/2019/84

\section{(c) $(1) \ominus$}

In 2016, there were nearly 1.8 million new HIV infections, 160,000 of which were among children. 19.5 million people were accessing ART in 2016.

\section{Burden of Disease in India}

India has the third largest HIV epidemic in the world. Overall, India's HIV epidemic is slowing down, with a $32 \%$ decline in new HIV infections $(80,000$ in 2016), and a $54 \%$ decline in AIDS-related deaths between 2007 and 2015. Heterosexual sex accounted for $87 \%$ of new infections in 2015 in India.

The five states with the highest HIV prevalence (Nagaland, Mizoram, Manipur, Andhra Pradesh and Karnataka) are in the south or east of the country.

\section{Human Immunodeficiency Virus (HIV)}

Is a blood-borne, sexually transmissible virus. Risk factors includes: Unprotected sexual intercourse, Multiple number of sexual partners, Prior or current STDs, Sharing of intravenous drug paraphernalia, Receipt of blood products, Mucosal 
contact with infected blood or Needle-stick injuries, Maternal HIV infection (For new-born, Infants \& Children\}.

\section{HIV and CD4 Count}

The CD4 count [2] varies by up to $20 \%$ from day to day and is also transiently reduced by intercurrent infections. Due to this variability, major therapeutic decisions should not be taken on the basis of a single count. This is particularly important when ART is being initiated in patients who do not fulfil the clinical criteria to start ART.

The normal CD 4 count is $>500$ cells/cubic $\mathrm{mm}$ [3]. The rate of decline in CD4 count is highly variable. People with CD4 counts between 200 and 500 cells have a low risk of developing opportunistic infections. Morbidity due to inflammatory dermatosis, herpes zoster, oral candidiasis, tuberculosis, bacterial pneumonia and HIV- related immune disorders (e.g. immune thrombocytopenia) becomes increasingly common as CD4 counts decline. Once the count is below 200 cells/cubic $\mathrm{mm}$, there is severe immune suppression and a high risk of AIDS defines conditions. It is important to note that patients can be asymptomatic despite very low CD4 counts and that major opportunistic diseases occasionally present with high CD 4 counts.

The CD4 count should be performed every 3-6 months in patients not yet eligible for ART and is usually done at similar intervals in patients on ART.

\section{MATERIALS AND METHODS}

The present study was conducted at KPS PG Institute of Medicine and ART -plus centre, G.S.V.M. Medical College, Kanpur. This is a hospital based [observational] Cohort study carried out between Dec. 2015 to July 2017. A total 100 adult HIV positive patients registered at ART- plus centre were followed up during the study period. Sample was divided into 4 groups group A 18-20 years, Group B 20-40 years, Group C 40-60 years and Group D 60-80 years. CD4 count was done at 2 weeks, 4 months, 8 months, 12 months, 16 months, and 20 months of ART therapy.

\section{Method of Collection of Data}

All patients were interviewed and clinically examined. Informed consent was obtained from all subjects. Patient confidentiality was maintained.

\section{Study Period}

Dec. 2015 to July 2017.

\section{Place of Study}

LLR and Associated Hospitals, GSVM Medical College Kanpur and ART plus centre Kanpur (UP).

\section{Design of The Study}

This is a hospital based [observational] Cohort study conducted on adult HIV seropositive patients.

\section{Inclusion Criteria}

- $\quad$ Subjects with HIV serology positive by ELISA test.

- Subjects consenting to take part in study.

- All male and female patients $>18$ years and $<80$ years of age.

\section{Exclusion Criteria-}

- Abnormal Renal function with serum creatinine $>1.5$ $\mathrm{mg} \%$.

- $\quad$ SGOT/SGPT levels more than 4 times normal range.

\section{Statistical Analysis}

The data collected on predesigned and pretested questionnaire/record sheet was compiled and master table was made on EXCEL accordingly. To fulfil the objectives of the present research, most appropriate statistical tools (One-way repeated measures ANOVA analysis) were applied to analyse the data and conclusions were drawn accordingly.

\section{Investigations}

HIV (Serology) by ELISA, CD4 Count (Flow cytometry), Fasting lipid profile, Random blood sugar, Complete Haemogram, Liver Function Test, Renal function test, X-ray chest PA view, Urine pregnancy test.

\section{RESULTS}
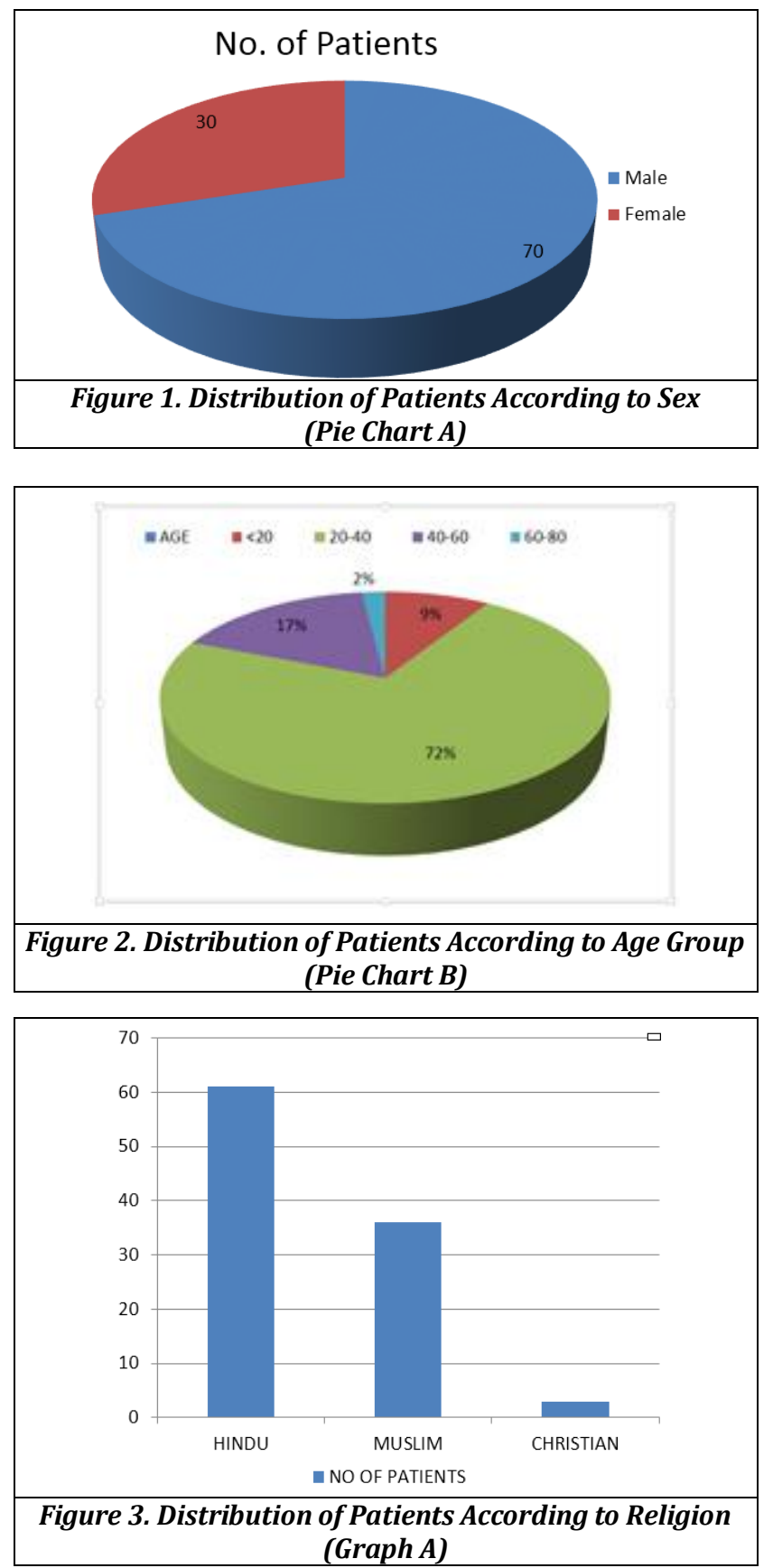


\begin{tabular}{|c|c|c|c|c|c|c|c|c|}
\hline $\begin{array}{c}\text { Age } \\
\text { Group }\end{array}$ & $\begin{array}{c}\text { Pre-ART } \\
\text { CD4 Mean } \\
\text { Value } \\
\pm\end{array}$ & $\begin{array}{c}\text { 2 Weeks } \\
\text { Post ART } \\
\text { CD4 Mean } \\
\text { Value } \pm\end{array}$ & $\begin{array}{c}\text { 4 Month } \\
\text { Post ART } \\
\text { CD4 Mean } \\
\text { Value } \pm \\
\text { SD }\end{array}$ & $\begin{array}{c}\text { 8 Months } \\
\text { Post ART } \\
\text { CD4 Mean } \\
\text { Value } \pm \\
\text { SD }\end{array}$ & $\begin{array}{c}\text { 12 Months } \\
\text { Post ART } \\
\text { CD4 Mean } \\
\text { Value } \pm \\
\text { SD }\end{array}$ & $\begin{array}{c}\text { 16 Months } \\
\text { Post ART CD4 } \\
\text { Mean Value } \pm \\
\text { SD }\end{array}$ & $\begin{array}{c}\text { 20 Months } \\
\text { Post ART CD4 } \\
\text { Mean Value } \pm \\
\text { SD }\end{array}$ & $\begin{array}{c}\text { Value } \\
\text { SD }\end{array}$ \\
\hline 18-20 Yrs. (n=9) & $215 \pm 9.287$ & $234 \pm 7.710$ & $289 \pm 10.513$ & $316 \pm 11.769$ & $324 \pm 7.259$ & $345 \pm 9.752$ & $380 \pm 13.090$ & $<0.001$ \\
\hline 20-40 Yrs. (n=72) & $224 \pm 8.672$ & $246 \pm 8.885$ & $311 \pm 16.122$ & $333 \pm 35.482$ & $357 \pm 16.673$ & $377 \pm 19.035$ & $396 \pm 17.740$ & $<0.001$ \\
\hline 40-60 Yrs. (n=17) & $231 \pm 12.049$ & $264 \pm 18.261$ & $274 \pm 19.161$ & $290 \pm 20.476$ & $306 \pm 20.475$ & $325 \pm 18.142$ & $345 \pm 18.722$ & $<0.001$ \\
\hline $60-80$ Yrs. (n=2) & $211 \pm 9.899$ & $230 \pm 16.971$ & $249 \pm 28.991$ & $265 \pm 38.891$ & $274 \pm 41.012$ & $286 \pm 34.648$ & $297 \pm 38.831$ & $<0.001$ \\
\hline \multicolumn{7}{|c|}{ Table 1. Mean Value and Standard Deviation Of CD4 Count During Pre-ART and During Art Period } \\
\hline
\end{tabular}

- $\quad$ One-way repeated measures ANOVA was applied. CD4 counts of patients of all groups were compared over time, from pre-ART time period to over periods of 2 wks., 4 months, 8 months, 12 months, 16 months, 20 months F-statistic was 1611.33 with a p value of $<0.00001$. This result rejected the null hypothesis that ART had no significant effect on CD4 counts of this study population early in the treatment phase.

- $\quad$ The difference between mean CD4 count in 18-20 years age group during pre-ART period and $20^{\text {th }}$ month of ART was found to be $164 \pm 19$. P value was $<0.001$ which was found to be significant.

- The difference between mean CD4 count in 20-40 years age group during pre-ART period and $20^{\text {th }}$ month of ART was found to be $172 \pm 20$. P value was $<0.001$ which was found to be significant.

- The difference between mean CD4 count in 40-60 years age group during pre-ART period and $20^{\text {th }}$ month of ART was found to be $114 \pm 18$. P value was $<0.001$ which was found to be significant.

- The difference between mean CD4 count in 60-80 years age group during pre-ART period and $20^{\text {th }}$ month of ART was found to be $86 \pm 29$. P value was $<0.001$ which was found to be significant.

- The difference of mean CD4 count in age group 18-20 years between 2 weeks \& 4 months was 65. P value was $<0.001$ which is significant.

- The difference of mean CD4 count in age group 20-40 years between 2 weeks \& 4 months was 65 . P value was $<0.001$ which is significant.

- The difference of mean CD4 count in age group 40-60 years between 2 weeks \& 4 months was 10 . P value was $<0.001$ which is significant.

- The difference of mean CD4 count in age group 60-80 years between 2 weeks \& 4 months was 19. P value was $<0.001$ which is significant.

It was concluded that there was more significant rise in CD4 count during 2 weeks to 4 months of ART in the younger age group of $18-20$ yrs. \& $20-40$ yrs.

\section{DISCUSSION}

Present study was conducted in HIV seropositive individuals, taken from ART plus Centre, LLR \& Associated Hospitals, G.S.V.M. Medical College Kanpur (U. P). The study was done during Dec. 2015 to July. 2017.
The study aims at recognizing the trend of CD4 count during the pre-ART period and during the course of ART. 100 seropositive HIV study subjects on HAART regimen were included in the study and were divided into four groups on the basis of age group into Group A 18-20 yrs., Group B 20-40 yrs., Group C 40-60 yrs. and Group D 60-80 yrs. CD4 count was noted before starting ART and also recorded CD4 Counts after 2 weeks of starting ART, 4 months of starting ART, 8 months of starting ART, 12 months of starting ART, 16 months of starting ART and after 20 months of starting ART.

There were 9 patients in $<20$ yrs. age group, 72 patients in 20-40 yrs. age group, 17 patients in 40-60 yrs. age group and 2 patients in 60-80 yrs. age group.

$70 \%$ of the subjects were males and $30 \%$ were females with male to female ratio of 2.333:1, comparable with the study of Yogesh Shukla et al and Grappin, Michèle et al had male to female ratio of 2.6.

Majority of the study population (72\%) belong to the age group of 20-40 years, with mean age of $33.91+10.4$ comparable with the study of Yogesh Shukla et al. had majority of the cases (81.45\%) between 20-45 years and Grappin, Michèle et al ${ }^{[4]}$ in which mean age was 40.8 years $(S D=9.54)$.

$73 \%$ of the study population was married of which $47 \%$ were male and $26 \%$ were females. $37 \%$ of the subjects were unmarried of which $23 \%$ were male and $4 \%$ were females, these observations were also comparable with the study of Yogesh Shukla et al.

$61 \%$ of the study population was Hindu, $36 \%$ of subjects were Muslim and $3 \%$ subjects were Christian.

Most of the study subjects (57\%) had their per capita income between 5-10 thousand, this is in contrast to the study of Yogesh Shukla et al in which most of the subjects (58.87\%) had per capita income/month of $<1,000$ rupees.

$81 \%$ patients were in the reproductive age group. The rise in CD4 count was maximum in $20-40$ age group $(172 \pm 20)$ followed by $18-20$ yrs. age group $(164 \pm 19)$ during the course of study.

The percentage of rise of CD4 count during pre-ART and after 20 months in 18-20 yrs. age group was 76\%, in 20-40 yrs. age group it was $76.78 \%$, in $40-60$ yrs. age group it was $49.35 \%$ and among $60-80$ yrs. age group it was $40.75 \%$ [5]

The percentage of rise of CD4 count between 2 weeks and $4^{\text {th }}$ months of ART was $23.07 \%$ among $18-20$ yrs. age group, $26.42 \%$ in $20-40$ yrs. age group, $3.78 \%$ rise among $40-60$ yrs. age group and $8.26 \%$ in $60-80$ yrs. age group. 


\section{CONCLUSION}

- Majority of the study subjects were males (70\%), compared to female subjects (30\%). Male: female ratio was 2.333: 1. Therefore, we concluded that HIV infection is more common in males.

- Majority of the subjects belong to age group of 20-40 years $(72 \%)$ followed by $40-60$ years $(17 \%)$ i.e. HIV infection is more common in reproductive age group.

- HIV infection is more common in married (73\%) (Including divorced and widowed) than unmarried (27\%) individuals.

- Majority of the subjects belong to Hindu religion (61\%) followed by Muslims (36\%).

- Majority of the subjects (57\%) had their income (in Rupees) between 5-10 thousands/month.

- During the study, significant rise in CD4 count was seen among all the age groups during ART period as compared to CD4 count during pre-ART period.

- It was concluded that there was more significant rise in CD4 count during 2 weeks to 4 months of ART in the younger age group of $18-20$ yrs. \& 20-40 yrs. probably because of better nutrition and family care and better immunity among the younger age group.

- From the study it was also concluded that patients receiving ART showed rising trend of CD4 count irrespective of the age group as compared to the CD4 count before starting ART. Morbidity was also less if the HIV seropositive patients were started ART early irrespective of the CD4 count and staging

\section{Study Limitations}

This study had some limitations too as the study group was small and the study was conducted purely on patients with Indian ethnic background. Only clinically stable patients were included in the study. Most of the patients were of poor economic background. Opportunistic infection could not be ruled out due to lack of resources.

\section{REFERENCES}

[1] Nash D, Wu Y, Elul B, et al. Program-level and contextual-level determinants of low-median CD4+ cell count in cohorts of persons initiating ART in eight subSaharan African Countries. AIDS 2011;25(12):1523-33.

[2] Grant PM, Kitch D, McComsey GA, et al. Low baseline CD4+ count is associated with greater bone mineral density loss after antiretroviral therapy initiation. Clin Infect Dis 2013;57(10):1483-8.

[3] McGrath N, Lessells RJ, Newell ML. Time to eligibility for antiretroviral therapy in adults with CD4 cell count $>500$ cells/microL in rural KwaZulu-Natal, South Africa. HIV Med 2015;16(8):512-8.

[4] Koenig SP, Bernard D, Devieux JG, et al. Trends in CD4 count testing, retention in pre-ART care, and ART initiation rates over the first decade of expansion of HIV services in Haiti. PLoS One 2016;11(2): e0146903.

[5] Rosen S, Fox MP. Retention in HIV care between testing and treatment in sub - Saharan Africa: a systematic review. PLoS Med 2011;8(7):e1001056. 